\title{
Comparative Analysis of Coil Structures and Orientations of Single Transmitter and Multi Receivers Wireless Power Transfer System
}

\author{
$\mathrm{CH}_{\text {Jagadeesh }}{ }^{*}$ and Phaneendra Babu Bobba ${ }^{1}$ \\ ${ }^{1}$ Department of EEE, GRIET, Hyderabad, India
}

\begin{abstract}
Single transmitter and multi receiver (STMR) based WPT system is used to power multiple loads at a time. It consists of some limitations like long distance power transfer, mutual inductance between receiver coils and misalignment of receiver coils. this paper is going to give a detailed information about different designs of STMR, which are going to overcome the limitations of STMR. Different designs proposed by different authors are wireless power repeater system with single coil in each repeater, wireless power repeater system with two coils in each repeater, spherical strongly coupled magnetic resonant, square shape coils, maglev train IPT system and cube shaped unidirectional flux transmitter type. The above-mentioned designs are analysed and concluded a best design from it, depending up on applications and discussed about the control systems used in STMR.
\end{abstract}

\section{INTRODUCTION}

Wireless power transfer system (WPT) is a technology used to transfer power from one circuit to another circuit through an air. There are many types of models of transferring power from one circuit to other like single transmitter to multi receivers (STMR), A non-resonance inductive coupled system, a resonant inductively coupled system, an strongly coupled magnetic resonance (SCMR), etc., transferring power from a single transmitter to multi receiver (STMR) is a technology developing to increase the utilisation of wireless power transfer instead of wire transfer technology. STMR has many applications like charging of electronics devices, charging of electric vehicles, Etc. important parameter to control in STMR is size of the coils, due to utilizing of compensation technology in WPT, size of it is increasing. To make it compact, combining the compensation and main circuits is a possible method to decrease the size requirement and efficiency increment [3].
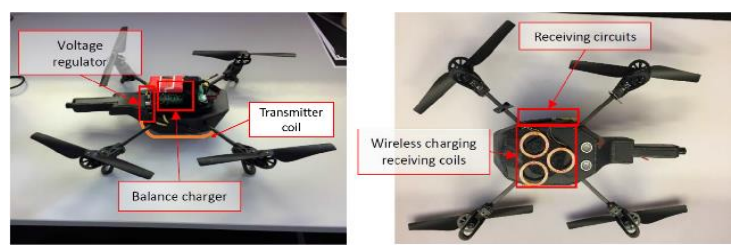

Fig1: Basic schematic diagram of STMR [26].
STMR is a system in which, there will be only one transmitter but "N" number of receivers as shown in fig (1), as application of drone battery charging. The main advantage of it is it can charge no of load at a time. limitations of STMR are Efficiency cannot be maintained high for long distance for many receivers by single transmitter, Coupling coefficient effect in receiver coils, Misalignment between transmitter and receiver coils. same frequency should be maintained between all the receiver coils to achieve high efficiency in the system.

This paper consists of different designs of STMR to overcome its limitations. Different designs of STMR are listed and analysed in section II, a comparison between different designs of STMR are given in section III, control systems used in STMR are explained in section IV and given detailed conclusion up on STMR's in section V.

\section{Different Designs of STMR System}

The following are the different evolutions in coil design to improve the efficiency in the STMR system

2.1 wireless power repeater system with single and two coil in each repeater 
2.2 Spherical Design Strongly Coupled Magnetic Resonance

\subsection{Square Shape Designs and its Analysis.}

\subsection{Maglev train IPT system.}

\subsection{Cubic shape transmitter}

Above designs are the solutions for the disadvantages of STMR system, mentioned in the introduction part I. Designs explained in part "A" and " $\mathrm{B}$ " are used to transfer the power to long distance and design analysed in " $\mathrm{C}$ " is used to transfer the power in all the directions and in part " $\mathrm{D}$ " is going to give information and importance of the energy management system in STMR.

\subsubsection{Wireless power repeater system with single coil in each repeater}

The design of wireless power repeater system with single coil in each repeater is shown in table1 figure (a). It consists of ' $N$ ' number of repeaters with only one coil in it, separated with an equal amount of distance between them. N-1 number of loads are connected to each coil in series, from the repeater-2 onwards. A high frequency power supply is given to the transmitter coil of the system. The power is transferred from transmitter coil to load connected to repeater one through the coil present in repeater one by mutual inductance principle. The coil present in repeater one will act as transmitter coil to the next repeater and power is transferred to next repeaters load through the coil present in that repeater. In the same manner the power is transferred to all loads present in each repeater one by one.
Wireless power repeater system equivalent circuit diagram is shown in tablel figure (b). The system should operate in resonate frequency to achieve maximum efficiency, it can be achieved by satisfying the equation (2.1)

$$
\omega_{0}=\frac{1}{\sqrt{L_{n} C_{n}}} n=0,1,2, \ldots N
$$

Where $L_{n}$ is the inductance of $n^{\text {th }}$ coil and $C_{n}$ is the compensation capacitance of $n^{\text {th }}$ coil.

Mutual inductance is designed as

$$
M_{n}=K_{n} \sqrt{L_{n-1} L_{n}}
$$

Reflected impedance of each coil as shown in fig(2) is

$$
Z_{n-1}=\frac{\left(\omega_{0} M_{n}\right)^{2}}{R_{n}+Z_{n}} \mathrm{n}=1,2,3 \ldots \mathrm{N}
$$

Where $\mathrm{N}=$ number of repeaters.

The power ratio between coil-n and coil-(n-1) is

$\gamma_{n}=\frac{P_{R n-1}}{P_{R n}}=\frac{R_{n-1}}{R_{n}} \cdot \frac{R_{n}+Z_{n}}{Z_{n-1}} \mathrm{n}=2,3,4 \ldots \mathrm{N}$

By substituting equation (2.3) in to equation (2.4) we get

$\gamma_{n}=\frac{R_{n-1}}{R_{n}} \frac{\left[1+\frac{1}{\gamma_{n+1}}+\frac{1}{\gamma_{n+1} \gamma_{n+2}}+\cdots+\frac{1}{\gamma_{n+1} \cdots \gamma_{N}}\right]^{2} R_{n}^{2}}{\left(\omega_{0} M_{n}\right)^{2}}, \mathrm{n}=2, \ldots \ldots,($

$\mathrm{N}-1)$

Table1 schematic and equivalent circuits of different designs of STMR

Schematic diagram Equivalent circuit




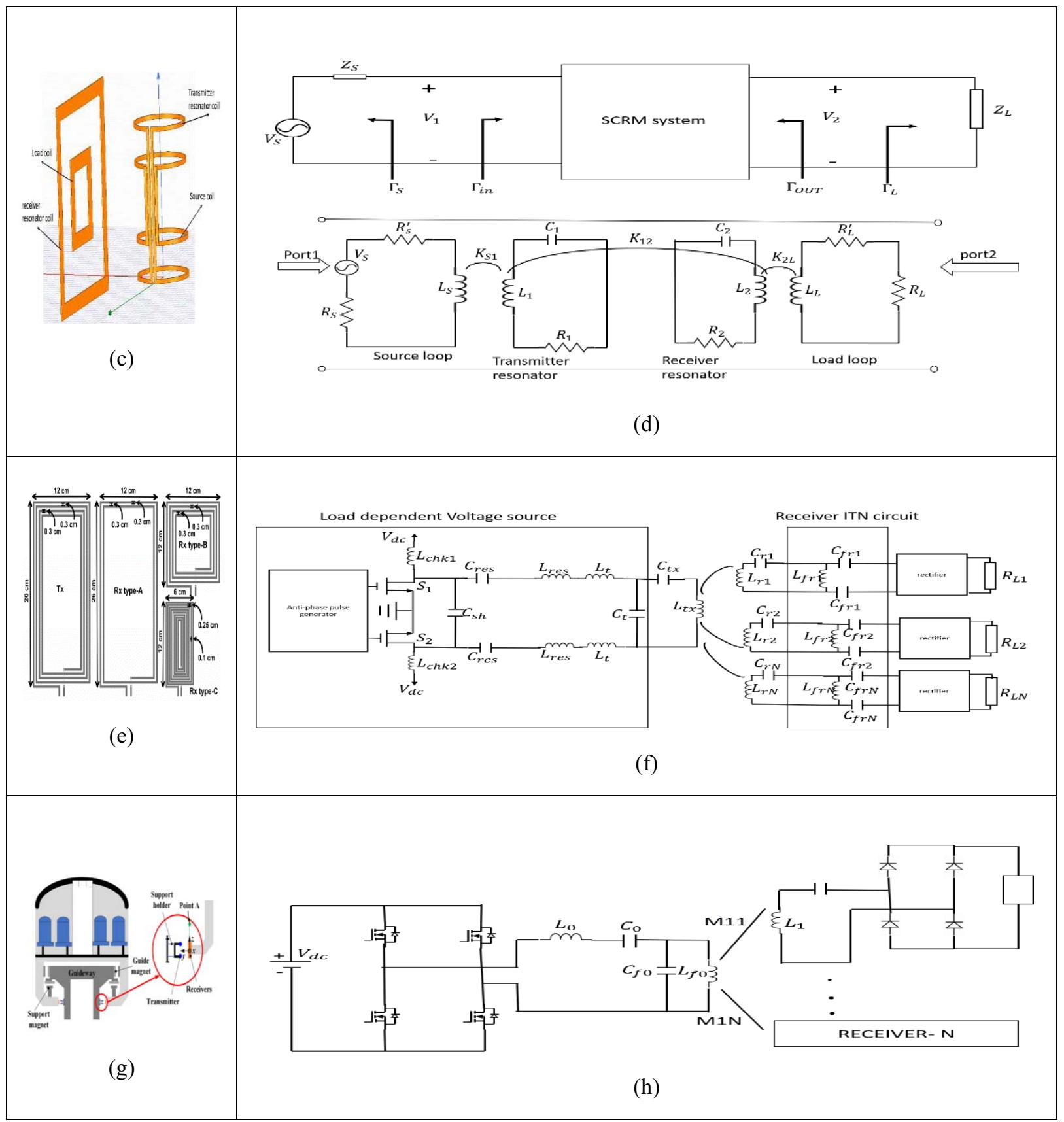

TABLE1 fig (a) Schematic diagram of single and two coils in each repeater of STMR. (b) Equivalent circuit of single and two receivers in single repeater. (c)Spherical shape transmitter STMR schematic diagram. (d) Spherical shape transmitter STMR equivalent circuit diagram. (e) Coils design of square shape [5] (f) Equivalent circuit diagram of load dependent voltage source control system. (g) Schematic diagram of maglev train WPT [6]. (h) Equivalent basic circuit of STMR.

From the equation (2.5), we can conclude that the maximization of power at loads depends on resistance of coil-n " $R_{n}$ " and coupling coefficient " $M_{n}$ ", equal power can be achieved by making $\gamma_{n}$ equals to one, it is possible by

$R_{n-1} R_{n}=\left(\frac{\omega_{0} M_{n}}{N-n+1}\right)^{2}, \mathrm{n}=2,3, \ldots \mathrm{N}$

When the system satisfies the equations (2.7) and (2.8), then it produces the more power in the load connected to the repeaters, which are connected near to the transmitter then that of far end.

$$
\begin{aligned}
& M=M_{1}=M_{2}=\cdots=M_{N} \\
& R=R_{1}=R_{2}=\cdots=R_{N}
\end{aligned}
$$

When the load resistance are maintained equal with different coupling coefficients leads to increment in self inductance, coil size and number of turns in coils of repeaters near to transmitter, then that of far end coils to produce equal amount of power. If 
there is no equality in load resistance of all the coils and also in all coupling

coefficient will leads to decrement in load resistance as the repeaters increases to maintain equal amount of power across each load. For the specifications given in table2 is simulated in ANSYS [1] and the result of it was specified in figure (2)

Table2. Parameters of single coil in each repeater system

\begin{tabular}{|c|c|c|}
\hline Parameters & $\begin{array}{c}\text { Design values } \\
\text { (single coil in } \\
\text { each repeater) }\end{array}$ & $\begin{array}{c}\text { Design values } \\
\text { (two coils in } \\
\text { each repeater) }\end{array}$ \\
\hline$V_{\text {in }}$ & $140 \mathrm{~V}$ & $30 \mathrm{~V}$ \\
\hline$f_{s w}$ & $1 \mathrm{MHz}$ & $200 \mathrm{KHz}$ \\
\hline$L_{0}-L_{8}$ & $110 \mu \mathrm{H}$ & $120 \mu \mathrm{H}$ \\
\hline$C_{0}-C_{8}$ & $230.3 \mathrm{pF}$ & $6.96 \mathrm{nF}$ \\
\hline$Q_{0}-Q_{8}$ & 450 & 200 \\
\hline$K$ & 0.035 & 0.49 \\
\hline$N$ & 8 & 6 \\
\hline$d$ & $400 \mathrm{~mm}$ & $30 \mathrm{~mm}$ \\
\hline$L_{f 0}-L_{f 6}$ & $\mathrm{NA}$ & $29.5 \mu \mathrm{H}$ \\
\hline$Q_{f 0}-Q_{f 6}$ & $\mathrm{NA}$ & 120 \\
\hline$C_{f 0}-C_{f 6}$ & $\mathrm{NA}$ & $21.84 \mathrm{nF}$ \\
\hline
\end{tabular}

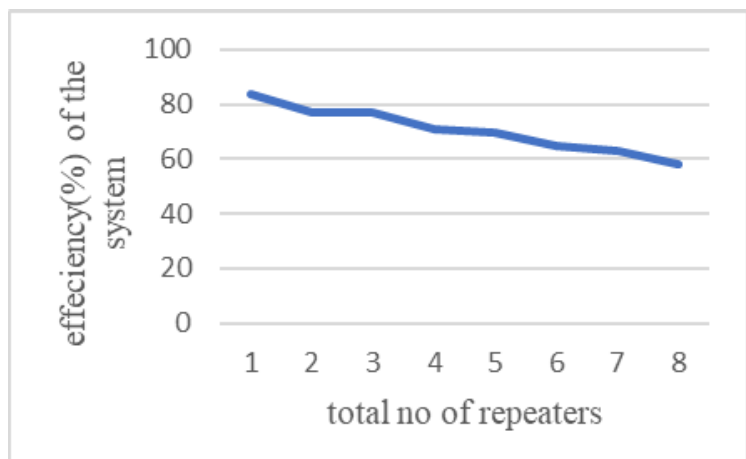

Fig. 2. Plot between the efficiency and no of repeaters in the system.

Figure (2) [1] gives the detail of the efficiency of the system as the number of repeaters increases with the quality factor of 300

\subsubsection{Wireless power repeater system with dual coils in each repeater}

In this type of system every repeater consists of two coils, one coil is to act as an receiver coil for the previous repeaters transmitter coil and the other coil will act as an transmitter coil to the next repeater and also it acts as inductance in LCC circuit. As shown in the table1 figure (a), two coils in a repeater are separated by the ferrite material plate, which is used to increase flux effect of two coils and not interrupting flux of two coils. the coils present in same repeater are placed with $90^{\circ}$ misalignment between them to maintain less coupling coefficient between them and transmitter coil of repeater and receiver coil of next repeater are placed with $0^{\circ}$ misalignment to maintain high amount of coupling coefficient between them as shown in table1 figure (a).

Wireless power repeater system with dual coils equivalent circuit diagram is shown in table1 fig (b). The two coils in $n^{\text {th }}$ repeater is considered as the $L_{n}(n=0,1,2 .$.$) and L_{f n}(n=0,1,2, \ldots)$ in circuit. $C_{n}, C_{f n}$ and $L_{f n}$ are the LCC compensation coil parameters of $n^{\text {th }}$ repeater.

LCC compensation circuit is used to increase the efficiency of the system by maintaining a unity power factor at the input of the circuit [3], it can be achieved by making the $L_{f n}$ of $n^{\text {th }}$ coil should resonates with $C_{f n}$ of $n^{\text {th }}$ coil and $L_{n}, C_{n}$ should resonates with $C_{f n}$ of $n^{\text {th }}$ coil, it is in equation form as the equation (2.9) and (2.10) respectively.

$$
\begin{aligned}
& \omega L_{f n}-\frac{1}{\omega C_{f n}}=0 \\
& \omega L_{n}-\frac{1}{\omega C_{n}}-\frac{1}{\omega C_{f n}}=0
\end{aligned}
$$

Super position theorem should apply to equivalent circuit shown in table1 fig (b) to obtain the LCC compensation circuit element values of each repeater from the current equations.

$I_{f 0}=\frac{V_{0}}{j \omega_{0} L_{f 0}}$

$I_{f n}=\frac{M_{n} I_{f(n-1)}}{L_{f n}}, n=1,2, \ldots N$

$I_{N}=\frac{V_{N}}{j \omega_{0} L_{f N}}$

$I_{n}=\frac{V_{0}}{j \omega_{0} L_{f n}}+\frac{M_{n+1} I_{n+1}}{L_{f n}}, n=0,1,2,3 \ldots N$

Where $I_{f 0}$ and $I_{f n}$ are currents through compensation inductance of $0^{\text {th }}$ repeater and $n^{\text {th }}$ repeater respectively, from theses currents it is clear that the load current does not depends on load resistance. Equation (2.15) should satisfy to get identical load currents.

$M_{1}=M_{2}=\cdots=M_{N}=L_{f 1}=L_{f 2}=. .=L_{f N}$

By considering the parasitic resistance of the main coil $\left(r_{n}\right)$ and compensation inductance coil $\left(r_{f n}\right)$, the reflection impedance of each repeater is 
as given in equation (21), (22) and (23). The final repeater has zero impedance due to no other continuation coil, given in equation (21).

$z_{f N}=0$

$Z_{n}=\frac{\left(\omega_{0} L_{f n}\right)^{2}}{r_{f n}+R_{n}+Z_{f n}}, n=0,1,2, \ldots, N$

$Z_{f n}=\frac{\left(\omega_{0} M_{f(n+1)}\right)^{2}}{r_{n+1}+Z_{n+1}}, n=0,1,2, \ldots,(N-1)$

To maintain a constant current at the load, we have to maintain same quality factor (as the parasitic resistance of coils depends on quality factor) at all the loads and same coupling coefficient between adjacent repeaters coils [2].

By substituting equations (2.16), (2.17) and (2.18) in (2.11), (2.12), (2.13) and (2.14), we get

$$
\begin{aligned}
& I_{0}=\frac{-V_{0}}{r_{0}+Z_{0}} \\
& I_{f n}=\frac{j \omega_{0} L_{f n} I_{f n}}{r_{f n}+R_{n}+Z_{f n}}, n=0,1,2, \ldots, N \\
& I_{n}=-\frac{j \omega_{0} M_{n} I_{f(n-1)}}{r_{n}+Z_{n}}, n=1,2, \ldots, N
\end{aligned}
$$

Values of the elements of system are calculated, listed in table I and implemented an hardware in research paper [2].

As shown in fig (3) the efficiency of the system is reaching its maximum efficiency at 0.14 normalised load resistance as $86.6 \%$. as the load resistance in each repeater is increasing the efficiency is getting a constant value.

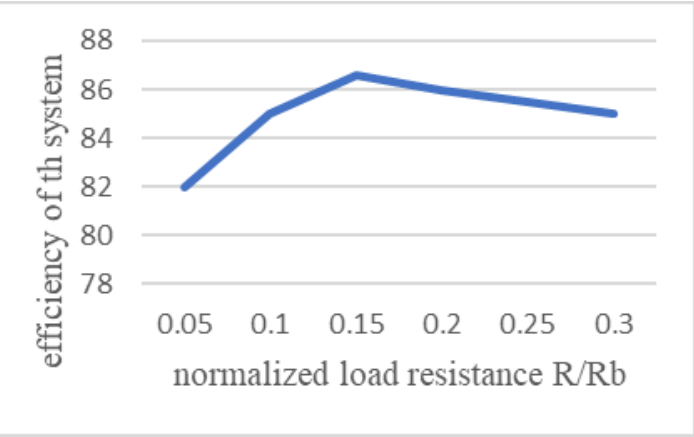

Fig. 3. Efficiency plot of the power repeater with dual coils in each repeater.

\subsection{Spherical Design Strongly Coupled Magnetic Resonance}

Strongly coupled magnetic resonance (SCMR) is a new technology in wireless power transfer to increase its efficiency. It consists of extra resonance coils separately to both transmitter and receiver coils as shown in table1 fig (c). SCMR type WPT is a system, which is very sensitive to angle misalignment between transmitter and receiver coils, it was proved by many papers [7],[23]

When a high frequency power supply is given to source coil (inner most), it will produce flux by which an emf is generated in the transmitter resonator coil. Current will passes through the transmitter resonator coil, due to short circuit of it.

Transmitter resonator coil will produce the flux by which the power is transferred to the receiver resonator coil. By the mutual inductance principle, power is transferred from receiver resonance coil to the load coil.

To transfer the power between resonator coils for a long distance, the resonator coils frequency should operate at maximum quality factor, it can get by equation (2.22) [5]

$f_{\max }=\frac{\frac{8}{c^{7}} \mu_{0}^{\frac{1}{7}} \rho^{\frac{1}{7}}}{4.15^{\frac{2}{7}} \pi^{\frac{11}{7}} r_{c}^{\frac{2}{7}} r^{\frac{6}{7}}}$

Two resonator coils should operate at same frequency and it is of maximum frequency $f_{\max }$ to obtain long distance power transfer. To obtain high efficiency the resonator

coils should resonate by connecting a series capacitor. The capacitor value to resonate the coils can be obtained by equation (2.23) [4]

$C=\frac{1}{\left(2 \pi f_{\max }\right)^{2} L}$

Where $\mathrm{L}$ is the equivalent inductance of resonator of transmitter or resonator of receiver. To analyse the powers of the system, it is converted to a twoport network as shown in table1 fig (d), it is easier to obtain S-domain parameters of the system.

Power gain of the system " $G_{T}$ " is the ratio of output power " $P_{L}$ " to the input power " $P_{a v g}$ " is defined in the equation (2.24) [4]

$G_{T}=\frac{P_{L}}{P_{\text {avg }}}=\frac{\left|S_{21}\right|^{2}\left(1-\left|\Gamma_{S}\right|^{2}\right)\left(1-\left|\Gamma_{L}\right|^{2}\right)}{\left|1-\Gamma_{S} \Gamma_{i n}\right|^{2}\left|1-S_{22} \Gamma_{L}\right|^{2}}$

From table1 fig (d), it is clear that the reflection coefficient from the source side is $\Gamma_{S}$, and the reflection coffecient from load is $\Gamma_{L}$, is given in equations (2.25) and (2.26) respectively.

$\Gamma_{S}=\frac{z_{S}-z_{0}}{z_{S}+z_{0}}$ 
$\Gamma_{L}=\frac{z_{L}-z_{0}}{z_{L}+z_{0}}$

Where $Z_{S}, Z_{L}$ are source and load impedance respectively and $Z_{0}$ is the characteristic impedance reference for the scattering parameters of the twoport network. Mismatch related to the input impedance of the two-port network is given as $\Gamma_{\text {in }}$ in equation (2.27) [4].

$\Gamma_{i n}=S_{11}+\frac{S_{12} S_{21} \Gamma_{L}}{1-S_{22} \Gamma_{L}}$

Considering the source and load impedance as $50 \Omega$, then the $\Gamma_{S}$ and $\Gamma_{L}$ from equation (2.25) and (2.26) will become zero and equation (2.27) will become $G_{T}$ as $\left|S_{21}\right|^{2}$ and the efficiency of the system depends on $\mathrm{S}$ parameters [4].

It consists of cylindrical shape of both source coil and transmitter resonator coil and the load side design has no change. Transmitter resonator coil has a radius of $76 \mathrm{~mm}$, and the height of it is $218.05 \mathrm{~mm}$, width of $12 \mathrm{~mm}$ and thickness of $0.035 \mathrm{~mm}$. the dimensions of receiver coil is receiver resonator coil (outermost coil) of square shape with size of side length is $115 \mathrm{~mm}$, load coil (innermost coil) in square shape with a length of $57.5 \mathrm{~mm}$ and thickness of copper strip is taken as $0.035 \mathrm{~mm}$.

Figure (4) gives the efficiency plot of the spherical SCMR with respect to angle misalignment between transmitter and receiver coils. efficiency of the system is maintaining in between $70-80 \%$, there is no discontinuous in the efficiency curve at $90^{\circ}$ and $270^{\circ}$. Depending up on the applications, the system will give output in all the angles.

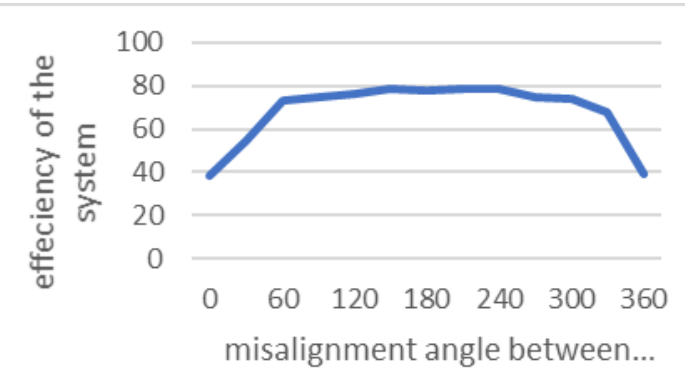

Fig (4): Efficiency plot of SSCMR for different misalignment angles.

\subsection{Square Shape Designs and its Analysis}

The coils design and distance between the transmitter coil and receiver coil will make a more effect on transfer efficiency of power in WPT system. square coils with different dimensions are designed and tested [5]. The receiver coils are designed with three different dimensions as shown in table1 fig (e) and named it as type-A, type-B and type-C. the transmitter coil with different dimensions of receiver coils are with different styles are placed in table 3 , and given it a case numbers from 1 to 9 .

Table 3: Different cases of receiver coils arrangement on transmitter coil

\begin{tabular}{|c|c|c|}
\hline Charging case & $\begin{array}{c}\text { Receivers } \\
\text { design type }\end{array}$ & $\begin{array}{c}\text { No of } \\
\text { receivers }\end{array}$ \\
\hline 1 & Rx type-A & 1 \\
\hline 2 & Rx type-B & 2 \\
\hline 3 & $\begin{array}{c}\text { Rx type-B, Rx } \\
\text { type-C }\end{array}$ & 1,2 \\
\hline 4 & Rx type-C & 4 \\
\hline 5 & $\begin{array}{c}\text { Rx type-B, Rx } \\
\text { type-C }\end{array}$ & 1,1 \\
\hline 6 & Rx type-C & 3 \\
\hline 7 & Rx type-C & 2 \\
\hline 8 & Rx type-B & 1 \\
\hline 9 & Rx type-C & 1 \\
\hline
\end{tabular}

Equivalent circuit of the system is given in table1 fig (f), it consists of four major parts as load dependent voltage source, PCR, receiver ITN circuit and rectifiers at load. Load dependent voltage source (LVS) is a controlling circuit used to control the transmitter power to transfer the power only to those receivers which are in ON state. This transmitter controlling circuit will operate according to the reference impedance value given by the operator of the system. Transmitter side ITN circuit and receiver side ITN's circuits are used to maintain same impedance to transmitter input and rectifier input respectively, so that the power produced by the transmitter will matches with the receivers receiving power.

Table 4: parameters and its values of the system.

\begin{tabular}{|c|c|c|}
\hline blocks & Parameters & Values \\
\hline \multirow{4}{*}{$\begin{array}{c}\text { Transmitter } \\
\text { side }\end{array}$} & $C_{r e s}$ & $1100 \mathrm{pF}$ \\
\cline { 2 - 3 } & $L_{t}$ & $1.0 \mu \mathrm{H}$ \\
\cline { 2 - 3 } & $C_{t}$ & $690 \mathrm{pF}$ \\
\cline { 2 - 3 } & $C_{s h}$ & $250 \mathrm{pF}$ \\
\cline { 2 - 3 } & $L_{c h k}$ & 47 \\
\hline \multirow{2}{*}{$\begin{array}{c}\text { Common to } \\
\text { receivers }\end{array}$} & $C_{t x}$ & $95 \mathrm{pF}$ \\
\hline $\begin{array}{c}\text { Receiver type- } \\
\text { A }\end{array}$ & $C_{L}$ & $40 \mu \mathrm{F}$ \\
\cline { 2 - 3 } & $L_{r, i}$ & $0.582 \mu \mathrm{H}$ \\
\hline
\end{tabular}




\begin{tabular}{|c|c|c|}
\hline & $C_{r x, i}$ & $280 \mathrm{pF}$ \\
\hline \multirow{2}{*}{$\begin{array}{c}\text { Receiver type- } \\
\text { B }\end{array}$} & $L_{r, i}$ & $0.5 \mu \mathrm{H}$ \\
\cline { 2 - 3 } & $C_{r, i}$ & $3200 \mathrm{pF}$ \\
\cline { 2 - 3 } & $C_{r x, i}$ & $200 \mathrm{pF}$ \\
\hline \multirow{3}{*}{$\begin{array}{c}\text { Receiver type- } \\
\text { C }\end{array}$} & $L_{r, i}$ & $0.568 \mu \mathrm{H}$ \\
\cline { 2 - 3 } & $C_{r, i}$ & $3000 \mathrm{pF}$ \\
\cline { 2 - 3 } & $C_{r x, i}$ & $129 \mathrm{pF}$ \\
\hline
\end{tabular}

Different cases provided in table 3 , are implemented with a distance of $3 \mathrm{~cm}$ between the transmitter and receiver coils. The system was operating at $6.78 \mathrm{MHz}$ frequency with parameters specified in table 4. The system efficiency and output power for different cases had obtained as shown in fig (5) [5], it is clear that as the number of receivers are increasing the system efficiency is decreasing. Maximum efficiency of the system was reached by the single receiver system of about $85.5 \%$ and the system efficiency for all cases are maintaining above $70 \%$.

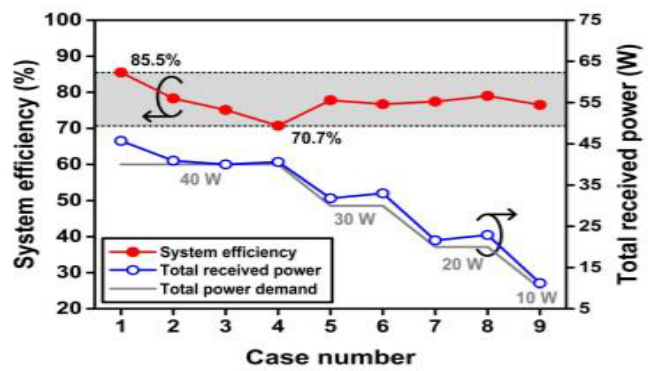

Fig. 5. Efficiency and power of the system[5].

\subsection{Maglev train IPT system}

Two litz wire is running throughout the track on either sides of track and it acts as an transmitter coil to transfer power to train. The receivers attached to the train will collect the power from the litz wire, without direct connection to it [6].

Receiver coil has a layers of aluminum plate, ferrite bars, limit board, coil and shall and placed one up on other in a layers. Ferrite bars are used to increase the flux density at the receiver coil, to increase the system efficiency. Limit board and shells are used to hold the ferrite bars and receiver coil respectively. Design of ferrite bars are modified to the bars placed exactly up on coil to increase the system efficiency and to reduce system cost.

System equivalent circuit as shown in fig (10), LCC compensation is used at transmitter side and series capacitor compensation is used at receiver side. The system resonance frequency is given as

$$
\omega_{0}=\frac{1}{\sqrt{L_{21} C_{21}}}=\frac{1}{\sqrt{L_{22} C_{22}}} \ldots=\frac{1}{\sqrt{L_{2 n} C_{2 n}}}
$$

Mutual inductance in between the transmitter and all the receivers are considering as ideally equal and also the load resistance connected to all receivers are also considered as equal value. the values of compensation parameter are derived and presented in following equations [6].

$L_{f 1}=M \frac{V_{A B}}{V_{a b}}, C_{f 1}=\frac{1}{\omega_{0}^{2} L_{f 1}}$
$C_{1}=\frac{1}{\omega_{0}^{2}\left(L_{1}-L_{f 1}\right)}, C_{2}=\frac{1}{\omega_{0}^{2} L_{2}}$

Maximum power obtained at a single receiver is

$P_{\max }=\frac{M^{2} V_{A B}^{2}}{L_{f 1}^{2} R^{\prime}}$

Tested results of the system in research paper [6], with 10 turns in it and a two wires passing through tack as a transmitter. 100 ferrite bars are used according to the results specified in table1 figure (g) will clearly says that the efficiency of the system had reached to $92 \%$ with the received power at receivers are $2.57 \mathrm{KW}, 2.59 \mathrm{KW}$ and $2.69 \mathrm{KW}$.

\subsection{Cubic shape transmitter}

To increase the efficiency of WPT system for a long distance by increasing of flux density can be achieved by the mono directional cubic design of transmitter. Transmitter coil is wound by a litz wire on edges of sides of cube by forming a 12dipoles. A ferrite bar is considered as the core to wound the coil. There are many possible ways to wound wire as a shape of cube in a continuous manner. As shown in figure (6) the wire is wound in such a way that all the 12 dipoles of cube are producing same direction of flux.

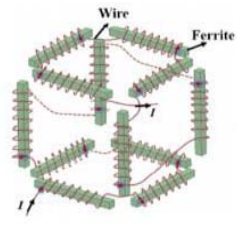

(a)

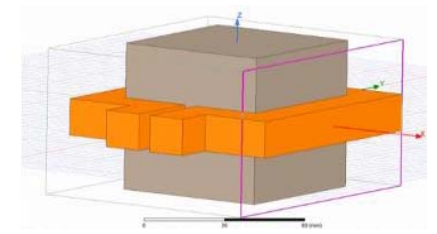

(b)
Fig. 6. (a) Cubic shape transmitter [7] and (b)1D shape receiver

Receiver coil was simulated in ANSYS and obtained that a 1D shaped coil with 4 dipole will produce a maximum flux distribution than a 2D OR 3D shaped coils [7]. 
Equivalent circuit diagram is as shown in table1 figure (h), general formulae of single transmitter and multi receivers power transfer efficiency (PTE) by neglecting mutual inductance between the receiver coils is given as

$\mathrm{PTE}=\frac{\sum_{\mathrm{i}=1}^{\mathrm{n}} \mathrm{z}_{\mathrm{Ri}} \frac{\mathrm{R}_{\mathrm{Li}}}{\mathrm{R}_{\mathrm{i}}+\mathrm{R}_{\mathrm{Li}}}}{\left(\mathrm{R}_{\mathrm{t}}+\sum_{\mathrm{i}=1}^{\mathrm{n}} \mathrm{z}_{\mathrm{Ri}}\right)}$

Where "I" is the count of receivers and $Z_{R i}$ is

$Z_{R i}=\frac{\left(\omega M_{t i}\right)^{2}}{R_{L i}+R_{i}}$

When we neglect coil resistance due to load $R_{L i}$ will be more larger than coil resistance $R_{i}$, then the PTE can be deduced as PTE $=\frac{1}{\frac{R_{\mathrm{t}}}{\sum_{\mathrm{i}=1}^{\mathrm{n}} z_{\mathrm{ri}}}+1}$

According to coupling theory, the current through the receiver coil can be taken as

$I_{r i}=\frac{-j \omega M_{t i}}{\left(R_{L i}+R_{i}\right)\left(\sum_{i=1}^{n} z_{R i}+R_{t}\right)} V_{s}$

Output power from $i_{t h}$ load is

$P_{i}=\frac{\left(\omega M_{t i}\right)^{2} V_{s}^{2}}{\left(R_{L i}+R_{i}\right)^{2}\left(\sum_{i=1}^{n} Z_{R i}+R t\right)^{2}} R_{L i}$

any two receiver coils power ratio can be calculated as

$\frac{P_{i}}{P_{j}}=\frac{P T E_{i}}{P T E_{j}}=\frac{M_{t i}^{2}\left(R_{j}+R_{L j}\right)^{2} R_{L i}}{M_{t j}^{2}\left(R_{i}+R_{L i}\right)^{2} R_{L j}}$

cube shape transmitter and 1D shaped receiver coils with $20 \mathrm{~cm}$ distance between them are analyzed and hardware results were specified in figure (7). it is concluding that as the number of receivers are increasing the efficiency of the system is also increasing by decreasing the power deliver to each other to supply power to all the receivers coupled to it.

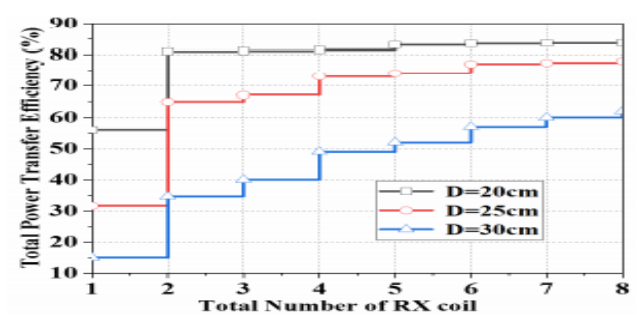

Fig. 7. Efficiency plot of cube structure WPT [7]

\section{Different control systems used in STMR}

\section{1 zero voltage switching controlling system}

The zero-voltage switching is a control used at transmitter side in inductive resonance STMR. It is used to control the power reached to the transmitter coil to obtain a quality power in the receiver coil by sensing the input current of transmitter coil controlling the inverter switches.

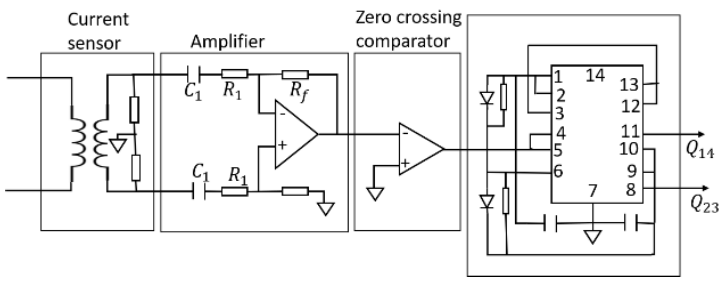

Fig. 8. Equivalent circuit diagram of zero voltage switching control system

As shown in fig (8) the inverter connected to transmitter coil switches $S_{2} \& S_{3}$ are turned ON and switches $S_{1} \& S_{4}$ are turned OFF at the time of $t_{1}$ to $t_{3}$ and a negative resistance is occurring at that time due to the discharge of inner capacitance of switches $S_{1} \& S_{4}$. Main problem of occurring negative resistance is Switches $S_{2} \& S_{3}$ are not turning $\mathrm{ON}$ after immediate switching OFF of switches $S_{1} \& S_{4}$. To avoid this problem, the voltage of output of inverter should lead the output current of inverter and considering that lead time as " $\Delta t_{L}$ " and also should maintain the required delay time $\left(\Delta t_{D}\right)$ to discharge the capacitor at the switches.

To obtain the times " $\Delta t_{L}$ " and " $\Delta t_{D}$ ", the inverter output is derived as

$V_{I}=\sqrt{2} V_{\max } \sin (\omega t)$

Where $V_{\max }=2 \sqrt{2} \frac{V_{d c}}{\pi}$

Output current of inverter is derived as

$\int_{0}^{\Delta t_{D}} i_{T}=\int_{0}^{\Delta t_{D}} \frac{-\sqrt{2} P_{0} \sin \left(\omega t-\omega \Delta t_{L}\right)}{\eta V_{\max } \cos \left(\omega \Delta t_{L}\right)} d t \geq \frac{V_{d c} C_{0}}{2}$

If considered $\Delta t_{L}=\Delta t_{D}$ then the above equation is modified as

$\Delta t_{L} \geq \Delta t_{D} \geq \Delta t_{c}=\operatorname{acos}\left[\frac{1}{\left(1+\frac{V_{d c}^{2} C_{0} \omega \eta}{\pi P_{0}}\right)}\right] / \omega$

Fig (8) represents the schematic diagram of ZVS control, it consists of current sensor to sense the inverter output current, amplifier is used to amplify the signal, zero crossing compensator is 
used to sense the current at zero crossing and obtain gate pulse to inverter switches using driver and switches the inverter circuit to avoid a negative resistance effect at the output of inverter in every cycle [25-30]. Hardware is implemented by the author according to the given values in table and obtained the negative resistance free power at the output of inverter.

Table5 Parameters of the zero voltage controlling system

\begin{tabular}{|l|l|}
\hline Parameters & values \\
\hline$V_{d c}$ & $23 \mathrm{~V}$ \\
\hline$L_{\text {transmitter }}$ & $21.5 \mu \mathrm{H}$ \\
\hline$L_{\text {Receiver }}$ & $16.7 \mu \mathrm{H}$ \\
\hline$C_{\text {transmitter }}$ & $1.178 \mathrm{nF}$ \\
\hline$C_{\text {receiver }}$ & $1.517 \mathrm{nF}$ \\
\hline$Q_{\text {transmitter }}$ & 530 \\
\hline$Q_{\text {Receiver }}$ & 552 \\
\hline
\end{tabular}

\section{2 class E power amplifier control circuit.}

Replacing the inverter with load dependent voltage source at transmitter coil side will improve the closed loop efficiency of the STMR system. It can be achieved by using a classE power amplifier, which has a advantages like maintaining high efficiency output and removing harmonics in output.

As shown in fig (8) the transmitter coil is connected to DC supply through a two class-E power amplifier connected in anti-parallel and a Tx ITN circuit. Whenever the MOSFET $S_{1}$ is ON, the current will reaches to ground through the inductor
$L_{c h k 1}$ and MOSFET $S_{2}$ will be in OFF condition and supplying power to transmitter coil through $L_{c h k 2}$. When switch $S_{1}$ is in OFF state and switch $S_{2}$ will be in ON state, current will reaches to transmitter coil is through inductor $L_{c h k 1}$. It consists of resonance circuit which have a series connected inductor and capacitor to eliminate the harmonics in the output of amplifier. Transmitter ITN circuit has a parallel capacitor and two series inductor and they are designed in such a way that the transmitter coil should resonate with receiver coil to give a high efficient power to receiver coils. when we considered a high efficiency STMR system, then we can conclude that all the powers are equal and same current flows through out the system as shown in fig (8) and given in equation (3.5)

$P_{d c}=P_{t x}=P_{r x}$

Where " $P_{d c}$ " is a input power to power amplifier, " $P_{t x}$ "is a transmitter coil output power and " $P_{r x}$ " is a power reached to receive coils. we can conclude that the load current is controlling the transistor present in MOSFET of class-E power amplifier or in other words transistor is acting as a load current dependent voltage source [5]. As the load current depends on output voltage, we can conclude the class-E power amplifier circuit as load dependent voltage source. The equivalent circuit of total STMR system with class-E power amplifier is shown in fig(8) and obtained the efficiency plot given in $\operatorname{fig}(9)$ for different cases which includes different designs of receivers given in table3.

\section{Comparison of Different Designs of STMR}

Table 5: Comparison between different designs of STMR system

\begin{tabular}{|c|c|c|c|c|c|c|c|}
\hline & $\begin{array}{c}\text { Coil } \\
\text { structure }\end{array}$ & $\begin{array}{l}\text { Distance } \\
\text { Between } \\
\text { each Pair } \\
\text { of coils }\end{array}$ & $\begin{array}{l}\text { Coupling } \\
\text { coefficient } \\
\text { "K" }\end{array}$ & $\begin{array}{l}\text { Operating } \\
\text { frequency }\end{array}$ & $\begin{array}{l}\text { Maximum } \\
\text { Efficiency } \\
\text { of the } \\
\text { system } \\
(\%)\end{array}$ & advantages & disadvantages \\
\hline 2.1 .1 & $\begin{array}{l}\text { Wireless } \\
\text { power } \\
\text { repeater } \\
\text { system } \\
\text { with } \\
\text { single coil } \\
\text { in each } \\
\text { repeater }\end{array}$ & $400 \mathrm{~mm}$ & 0.035 & $1 \mathrm{MHz}$ & 84 & $\begin{array}{l}\text { Low cost. } \\
\text { Power } \\
\text { transfer can } \\
\text { achieve for } \\
\text { long distance. }\end{array}$ & $\begin{array}{l}\text { Not possible for } \\
\text { high power } \\
\text { applications. } \\
\text { Low efficiency. }\end{array}$ \\
\hline
\end{tabular}




\begin{tabular}{|c|c|c|c|c|c|c|c|}
\hline 2.1 .2 & $\begin{array}{l}\text { Wireless } \\
\text { repeater } \\
\text { system } \\
\text { with } \\
\text { single coil } \\
\text { in each } \\
\text { Repeater }\end{array}$ & $30 \mathrm{~mm}$ & 0.49 & $200 \mathrm{KHz}$ & 86.6 & $\begin{array}{c}\text { High } \\
\text { efficiency. } \\
\text { Load currents } \\
\text { are } \\
\text { independent } \\
\text { of load. }\end{array}$ & $\begin{array}{l}\text { Limitation in load } \\
\text { increment to } \\
\text { avoid change in } \\
\text { load currents of } \\
\text { each repeater. }\end{array}$ \\
\hline 2.2 & $\begin{array}{l}\text { Spherical } \\
\text { Design } \\
\text { Strongly } \\
\text { Coupled } \\
\text { Magnetic } \\
\text { Resonance }\end{array}$ & $70 \mathrm{~mm}$ & & $\begin{array}{l}27.12 \\
\mathrm{MHz}\end{array}$ & 79 & $\begin{array}{c}\text { Power can be } \\
\text { collected from } \\
\text { all directions } \\
\text { of transmitter } \\
\text { coil. }\end{array}$ & Low efficiency. \\
\hline 2.3 & $\begin{array}{l}\text { Square } \\
\text { Shape } \\
\text { Designs } \\
\text { and its } \\
\text { Analysis }\end{array}$ & $30 \mathrm{~mm}$ & & $6.78 \mathrm{MHz}$ & 85.5 & $\begin{array}{l}\text { Different } \\
\text { power and } \\
\text { voltages coils } \\
\text { can receive } \\
\text { power on } \\
\text { single } \\
\text { transmitter } \\
\text { coil was } \\
\text { proven } \\
\end{array}$ & $\begin{array}{l}\text { Efficiency will } \\
\text { decreases due to } \\
\text { the mutual } \\
\text { inductance } \\
\text { between different } \\
\text { receivers }\end{array}$ \\
\hline 2.4 & $\begin{array}{c}\text { Maglev } \\
\text { train IPT } \\
\text { system }\end{array}$ & $40 \mathrm{~mm}$ & 0.052 & $85 \mathrm{KHz}$ & 92 & $\begin{array}{l}\text { Cost effective } \\
\text { for large } \\
\text { applications } \\
\text { like railway } \\
\text { WPT }\end{array}$ & $\begin{array}{l}\text { More losses, high } \\
\text { maintenance }\end{array}$ \\
\hline 2.5 & $\begin{array}{l}\text { Cubic } \\
\text { shape } \\
\text { transmitter }\end{array}$ & $200 \mathrm{~mm}$ & 0.013 & $84.5 \mathrm{KHz}$ & 85 & $\begin{array}{c}\text { Different coils } \\
\text { flux combined } \\
\text { to make a } \\
\text { bulk amount } \\
\text { of flux and to } \\
\text { obtain high } \\
\text { efficiency }\end{array}$ & $\begin{array}{l}\text { Construction is } \\
\text { difficult }\end{array}$ \\
\hline
\end{tabular}

Table 5 gives a detail comparison between different designs of STMR systems discussed in section 2. The comparison is done based on efficiency, coupling coefficient, distance between each pair of coils, operating frequency and there advantages with limitations.

\section{Conclusions}

This paper represents different efficient possibilities of transferring power to multi receivers through a single transmitter coil. The efficient designs of STMR-WPT are wireless power repeater system with single coil and dual coils in each repeater, spherical strongly coupled magnetic resonance, different designs of square shape, magliv train WPT system and cubic shape transmitter multi receiver system. Power repeater system with single coil is used for low power applications like supplying gate pulses to multi- level inverter and dual coil in each repeater has high efficiency used for high power applications. Cylindrical strongly coupled magnetic resonance system is designed to receive the power from transmitter from all the Directions $\left(360^{\circ}\right)$. Square shape coils with different voltage and power ratings are also working with good efficiency. As given in conclusion table the power with cube shape transmitter coil for long distance is best suitable to produce maximum efficiency and to avoid mutual inductance between receivers in the multi receiver system and load dependent control can be achieved by using class-E power amplifier.

\section{References}

1. F. Lu, H. Zhang, W. Li, Z. Zhou, Chong Zhu, Chenwen Cheng, Zhanfeng Deng, Xi Chen, Chunting Chris Mi, IEEE Trans, Pow. Elec. (2019). 
2. Chenwen Cheng, Fei Lu, Zhe Zhou, Weiguo $\mathrm{Li}$, Zhanfeng Deng, Fangyi Li, Chris Mi, IEEE Trans, Ind. Electron (2019).

3. Tianze Kan, Trong Duy Nguyen, Jeff C.White, Rajesh K.Malhan and Chris Mi, IEEE Trans. Power Electron (2016).

4. Daerhan Liu, d Stavros V. Georgakopoulos, IEEE Trans. Power Electron (2018).

5. Hansik Oh , Sungjae Oh, Hyungmo Koo , Woojin Choi, Jaekyun Shin, Keum Cheol Hwang, , Kang-yoon Lee and Youngoo Yang, IEEE Trans, Power Electron (2021).

6. Junjun Deng, Yuanqing Zhang, Shuo Wang, Zhenpo Wang, Ying Yang, IEEE Trans. Power Electron (2021)

7. Cancan Rong, Xiangrui He, Minghai Liu , Yuying Wang, Xiaobo Liu, Conghui Lu , Yingqin Zeng and Renzhe Liu, IEEE Trans. Power Electron (2021).

8. Y. Zhang, T. Lu, Z. Zhao, F. He, K. Chen, and L. Yuan, IEEE Trans. Power Electron (2014).

9. Z. Zhang and B. Zhang, IEEE Trans. Ind. Electron (2020).

10. Y. Yao, Y. Wang, X. Liu, Y. Pei, and D. Xu, IEEE Trans. Power Electron (2019).

11. Q. Zhu, Y. Guo, L. Wang, C. Liao, and F. Li, IEEE Trans. Ind. Electron (2015).

12. J. L. Villa, J. Sallan, J. F. S. Osorio, and A. Llombart, IEEE Trans. Ind. Electron (2012).

13. S. Li, W. Li, J. Deng, T. D. Nguyen, and C. C. Mi, IEEE Trans (2015).

14. J. Lee and B. Han, IEEE Trans. Power Electron (2015).

15. O. Jonah, S. V. Georgakopoulos, and M. M. Tentzeris, IEEE Wireless Power Trans (2013).

16. W. Junhua, S. L Ho, W. N. Fu, and Sun Mingui, IEEE Trans (2011).

17. F. Zhang, S. A. Hackwoth, X. Liu, L. Chengliu, and S. Mingui, in Proc. 2010 IEEE
Annu. Int. Conf. Eng. Medicine Biology Soc (2010).

18. Sample, D. Meyer, and J. Smith, IEEE Trans. Ind. Electron (2011).

19. W. Ng, C. Zhang, D. Lin, and S. Y. R. Hui, IEEE Trans. Power Electron (2014).

20. C. Zhang, D. Lin and S. Y. Hui, IEEE Trans. Power Electron (2016).

21. Z.Dang, Y. Cao and J. A. A. Qahouq, IEEE Trans. Power Electron (2015).

22. D. Liu, H. Hu and S. V. Georgakopoulos, IEEE Trans. Power Electron (2017).

23. O. Jonah, S. V. Georgakopoulos, and M. M. Tentzeris, IEEE Antennas Wireless Propag. Lett (2012).

24. D. Daerhan, O. Jonah, H. Hu, S. V. Georgakopoulos and M. M. Tentzeris. in Proc. IEEE Electron. Compon. Technol. Conf (2014).

25. shubin sun, Bo Zhang, Chao Rong, Xujian Shu, IEEE (2021).

26. Awaar, V.K., Jugge, P. \& Tara Kalyani, S. J Control Autom Electr Syst 30, 601(2019).

27. Awaar, Vinay Kumar, Praveen Jugge, S. Tara Kalyani, and Someshwara Thota, (IEEESEFET), (2021)

28. V. K. Awaar, P. Jugge and Tara Kalyani S, (IEEE IECON), Florence, (2016).

29. V. K. Awaar, P. Jugge and Tara Kalyani S, (IEEE PEDES), Trivandrum, (2016).

30. Ali Bin Junaid, Aleksay Konoiko, Yahya Zweiri, M. Necip Sahinkaya and Lakmal Seneviratne, Energies 